\title{
La lucha de clases por la tierra y por la democracia en Paraguay
}

\section{Arturo Ezquerro-Cañete*}

Resumen. El artículo ${ }^{1}$ explora el reciente cambio en la economía agraria de Paraguay hacia el agroextractivismo y sus efectos en la reconfiguración de la estructura de clases. Se analiza cómo dicha estructura de clase ha contribuido a las formas cambiantes que la lucha de clases (desde arriba y desde abajo) ha adquirido en $\mathrm{Pa}$ raguay en el curso de la prolongada transición del país a la democracia (1989-2008). Se centra en «el ascenso y la caída» del presidente Fernando Lugo (2008-2012) y estudia los procesos históricos específicos de formación de clases y del Estado en Paraguay que explican el golpe constitucional instigado por la clase terrateniente contra Lugo en 2012. Además, se argumenta que la burguesía terrateniente paraguaya ejerce un control oligárquico sobre el Estado, de tal forma que las posibilidades de una reforma agraria redistributiva continúan siendo muy complicadas en tanto no se produzcan cambios profundos, estructurales e institucionales en la sociedad y el Estado.

Palabras clave: Paraguay, agroextractivismo, lucha de clases, movimiento campesino, Fernando Lugo.

${ }^{1}$ Este artículo es una traducción actualizada del capítulo «Paraguay: class struggle on the extractive frontier» (Ezquerro-Cañete, 2018), publicado originalmente en The class struggle in Latin America (Petras y Veltmeyer, 2018).

${ }^{*}$ Candidato a doctor en estudios de desarrollo internacional, Saint Mary's University, Canadá; estudiante del Doctorado en Estudios del Desarrollo, Universidad Autónoma de Zacatecas, México. Correo-e: arturo_ezquerro@hotmail.co.uk 


\section{The class struggle for land and democracy in Paraguay}

Abstract. This article explores the recent change in Paraguay's agrarian economy towards agro-extractivism and its effects on the reconfiguration of the class structure. It analyses how this class structure has contributed to the changing forms that the class struggle (from above and from below) has taken in Paraguay in the course of the country's protracted transition to democracy between 1989 and 2008. It focuses on «the rise and fall» of President Fernando Lugo (2008-2012) and studies the specific historical processes of class and state formation in Paraguay that explain the parliamentary coup against Lugo in 2012, instigated by the landlord class. It is argued that the oligarchic control of the state by landed elites continues to impede the prospects for redistributive land reform, the prospects of which continue to be slim without substantial, even if partial, structural and institutional change within the state and in society.

Keywords: Paraguay, agro-extractivism, class struggle, peasant movement, Fernando Lugo. 


\section{Introducción}

El 22 de junio de 2012 el presidente electo de Paraguay, Fernando Lugo, fue removido de sus funciones por el Senado y reemplazado temporalmente por Federico Franco, miembro de una de las facciones de la coalición Alianza Patriótica para el Cambio (APC), que había llevado al propio Lugo al poder, situación que puso fin al incierto experimento democrático existente en el país desde 1989. Paraguay fue suspendido tanto de la Unión de Naciones Suramericanas (Unasur) como del Mercado Común del Sur (Mercosur) por dicha irregularidad democrática, y sólo fue readmitido tras la elección del nuevo presidente del gobierno Horacio Cartes, del Partido Colorado, en agosto de 2013.

El episodio anterior refleja la intensificación de los esfuerzos del imperialismo y de la derecha latinoamericana para abortar el ciclo progresista iniciado en los años 2000. En este sentido, el caso paraguayo (junto con el golpe militar de 2009 en Honduras) constituyó, quizá, una de las primeras etapas del retroceso de la llamada marea rosa, algo que se ha intensificado en los últimos años. Por un lado, se inauguró una tendencia emergente hacia «golpes de Estado inteligentes», por la cual los gobiernos de izquierda son derrocados y reemplazados por gobiernos de derecha, preferiblemente, sin apenas derramamiento de sangre y con un elemento de legitimidad popular e institucional (Cannon, 2016:119; en el caso de Dilma Rousseff en 2016 en Brasil, véase Santos y Guarnieri, 2016).

Aunque el presente estudio se centra en «el ascenso y la caída» de Fernando Lugo y en los avances multifacéticos de las fuerzas conservadoras a partir de entonces, comienza con la premisa de que el papel y las nuevas manifestaciones de la lucha de clases no pueden entenderse desde un 
aislamiento histórico. En efecto, según describe Marx en su concepción del materialismo histórico, en cada etapa del desarrollo capitalista puede encontrarse una forma correspondiente y distinta de la lucha de clases, basada en las fuerzas de resistencia a dicho avance. Por lo tanto, este trabajo empieza con una breve reflexión sobre los fundamentos históricos del Paraguay contemporáneo, en la que se trazan las dinámicas de represión y cooptación durante la dictadura de Alfredo Stroessner (1954-1989), así como el cambio más reciente en la economía agraria del país hacia el «agroextractivismo».

La sección dos se centra en la cuestión de la agencia y examina las clases sociales más importantes del país: la oligarquía terrateniente, el campesinado y las fuerzas del imperialismo. La siguiente sección explora cómo esta estructura de clase ha contribuido a las formas cambiantes que la lucha de clases (desde arriba y desde abajo) ha tomado en Paraguay en el curso de la prolongada transición del país a la democracia (1989-2008). En ese contexto, el presente estudio ubica el ascenso de Lugo al poder y traza la característica sobresaliente de la lucha de clases durante su efímera administración (20082012). Se analizan también los intereses de clase detrás del «golpe parlamentario» de junio de 2012. Finalmente, se ofrece un breve análisis de la lucha de clases bajo la administración de Horacio Cartes (2013-2018).

\section{Fundamento histórico}

\section{El régimen de Stroessner (1954-1989)}

El general Alfredo Stroessner presidió la dictadura más larga de América Latina del siglo XX, entre 1954 y 1989. Durante ese periodo, la corrupción 
generalizada y el clientelismo en sus diversas formas — desde el contrabando hasta el blanqueo de capitales y el robo al Estado- fueron justificados por Stroessner (en una entrevista en 1965) como «el precio de la paz», lo que convirtió a Paraguay en lo que Eduardo Galeano (1973:196) llamó el «reino de la corrupción institucionalizada». Stroessner también buscó justificar la tortura y la represión interna al vincular su medida contra todos los opositores, percibidos o reales, a la doctrina anticomunista de la Guerra Fría, lo que dio a su régimen una merecida reputación de brutalidad y abusos contra los derechos humanos, así como el apoyo económico y político de Estados Unidos. Mientras la deslealtad era castigada con persecución y represión, la lealtad garantizaba recompensas económicas y privilegios que incluían posiciones lucrativas en monopolios estatales, acceso a activos públicos y adquisición de tierras a través del Instituto de Bienestar Rural (IBR).

Kleinpenning y Zoomers (1991:279) explican que «a pesar del hecho de que la propiedad rural y las relaciones de tenencia eran muy desfavorables para la mayoría cuando el presidente Stroessner llegó al poder, hubo poca o ninguna rebelión campesina durante su régimen, y las masas rurales fueron incapaces de forzar al gobierno a mejorar su situación». La quietud del campesinado se explica por medio de una estrategia y una política en dos frentes: a) la colonización agrícola, en la que el régimen de Stroessner institucionalizó los lazos tradicionales patrón-cliente del campesinado y la élite rural a través de la tierra, y b) la represión por la que el régimen de Stroessner logró derrotar o «derribar» a los movimientos sociales involucrados en la lucha por la tierra.

En la década de 1960, el régimen de Stroessner, ante el estancamiento del crecimiento agrícola y una creciente preocupación por el extendido conflicto de tierras entre latifundistas y minifundistas, se embarcó en un 


\section{Arturo Ezquerro-CAÑEte}

ambicioso programa interno de colonización con la distribución de tierras estatales, sobre todo en el interior escasamente poblado y en las zonas fronterizas. El Estatuto Agrario de 1963 proporcionó una nueva base legal y se creó el IBR como la agencia gubernamental encargada de llevar a cabo esta reforma, con la intención declarada de aumentar el bienestar rural (Kleinpenning, 1984). En la práctica, sin embargo, mientras la reforma estaba nominalmente comprometida a probar el título de propiedad y el apoyo al campesinado sin tierra, la mayor parte de la tierra pública fue asignada a precios oficiales irrisorios a personas asociadas políticamente con el régimen (por ejemplo, Fuerzas Armadas, élites rurales, funcionarios del gobierno), que a su vez revendieron parte de esta tierra a precios de mercado muy favorables a empresas y colonos brasileños. El IBR también vendió tierras directamente a agencias y compañías inmobiliarias extranjeras (Kleinpenning, 1984).

Según un informe reciente de la Comisión de Verdad y Justicia (CVJ) acerca de la tenencia ilegal de tierras, entre 1954 y 2003 se asignaron 7 millones 851 mil 295 hectáreas (64 por ciento del total de tierras distribuidas y 19 por ciento de la superficie total de Paraguay), tanto a nacionales como a extranjeros, de manera irregular y clientelar (CVJ, 2008). El estudio examinó 200 mil 705 adjudicaciones de tierras y concluyó que muchos beneficiarios eran parientes del mismo Stroessner, o políticos y oficiales del ejército directamente asociados con su gobierno. Como resultado, «casi todos los miembros del Congreso también son miembros de la pequeña élite terrateniente de Paraguay, con títulos que se conservan directamente o en nombre de amigos y familiares» (Nickson, 2015:18).

Como quedará claro más adelante al analizar los casos de Nacunday y de Marina Kue, los vínculos con el Estado continúan permitiendo que 
la oligarquía rural mantenga su monopolio de acceso seguro a la tierra, a pesar de que dicho acceso a menudo se adquirió ilegalmente. La tierra así adquirida, o «políticamente constituida» (véase Wood, 1999:49-50; Vergara-Camus y Kay, 2018:22-26), se conoce en Paraguay con el nombre de «tierra malhabida», y continúa estando en el centro de los conflictos de tierras y de la cuestión agraria del país. En realidad fue a propósito de reclamar la propiedad de tierras por parte de Blas N. Riquelme, exsenador del Partido Colorado, que 17 personas fueron masacradas el 15 de junio de 2012, lo cual desencadenó la destitución de Fernando Lugo una semana más tarde, como se verá en detalle a continuación.

\section{De las agroexportaciones al «agroextractivismo»}

Durante gran parte de su historia Paraguay ha sido uno de los países que con mayor consistencia ha aplicado la estrategia de «economía abierta» para el crecimiento económico (Nickson y Lambert, 2002; Birch, 2014). A diferencia de la mayoría de los otros países latinoamericanos a mediados del siglo XX, particularmente de sus vecinos del Cono Sur, Paraguay nunca experimentó un periodo de industrialización que disminuyera la necesidad de importaciones, sino que basó su economía en un modelo de desarrollo agroexportador (Baer y Birch, 1984; Weisskoff, 1992). Parte de la razón de esto fue el poder de los grandes terratenientes y cabilderos agrícolas. Stroessner también desalentó la industrialización por miedo a la posibilidad de que ésta alentara el surgimiento de sindicatos, que podrían representar una amenaza para su gobierno. En consecuencia, en Paraguay no existe ni sector manufacturero significativo ni burguesía o proletariado 
industrial, lo que explica en parte por qué el movimiento campesino sigue siendo el actor social más importante en cuanto a desafiar al Estado y a la élite política.

La agricultura sigue siendo el mayor sector de la economía paraguaya, ya que representa más de un quinto de su actividad económica, una característica que la distingue del resto de América del Sur. Como señaló Kregg Hetherington (2009), Paraguay es el único país latinoamericano incluido en el World development report: agriculture for development, en el que el Banco Mundial considera que se ajusta a la categoría de «economía basada en la agricultura» (Banco Mundial, 2007:31). Además, si bien la contribución relativa de la agricultura disminuyó de forma constante y significativa durante las décadas de 1970 y 1980, de forma algo inesperada Paraguay es hoy una economía más agrícola que en 1990, de acuerdo a su participación en el producto interno bruto (PIB) (Birch, 2014). ${ }^{2}$

Desde finales de la década de 1990, el ritmo, la dirección y las consecuencias del modelo de desarrollo agrario paraguayo se han transformado radicalmente y se están convirtiendo cada vez más en características de un «agroextractivismo» (Rojas, 2014; Fogel, 2019; véase también Petras y Veltmeyer, 2014). Éste se manifiesta a través de la conversión de tierras cultivables para la producción doméstica de alimentos en tierras para la producción corporativa de productos agrícolas con múltiples usos, en tanto alimento, ración para animales (pienso), combustible o insumos industriales que pueden ser fácilmente intercambiables — llamados «cultivos flexibles» (flex crops) o «cultivos comodín» en el léxico de estudios agrarios críticos

\footnotetext{
${ }^{2}$ «La agricultura como porcentaje del PIB para el periodo de 1968 a 1988 promedió 14.2 por ciento, mientras que se situó en 18.4 por ciento para el periodo 2003-2010» (Borda, 2012, citado en Birch, 2014:288n2).
} 
(véase Borras et al., 2012). En ese sentido, Paraguay ha experimentado un marcado cambio respecto a la producción a pequeña escala de una variedad de cultivos agrícolas, tanto para el consumo interno como para la exportación, y también un marcado cambio hacia la monocultivación mecanizada a gran escala de la soja para los mercados mundiales de productos básicos.

Como resultado de tales desarrollos, junto con los altos precios de los productos básicos durante la década de 2000, Paraguay experimentó un crecimiento económico sostenido, lo que promedió 4.9 por ciento entre 2003 y 2013, marcado por oscilaciones económicas extremas a menudo conectadas a las condiciones climáticas, con un máximo de 13.6 por ciento en 2013 y un mínimo de -4.0 por ciento en 2009. Cabe destacar que en sólo dos años la economía pasó de una contracción de 4 por ciento del PIB en 2009, récord de medio siglo después de la grave y generalizada sequía de ese año y de la caída de los precios internacionales de los productos agrícolas, a un crecimiento récord del PIB de 13.1 por ciento en el año siguiente, gracias a una cosecha abundante en el periodo 2009-2010. Tras ello, la economía se desplomó 4.3 por ciento en 2011 y se contrajo de nuevo 1.2 por ciento en 2012 (a raíz de la severa sequía que azotó el país a finales de 2011 y principios de 2012), para luego volver a crecer 13.6 por ciento, siendo el país de más rápido crecimiento en la región (Cepal, varios años). 


\section{Arturo Ezquerro-CAÑete}

\section{Cuadro 1}

Área de siembra y producción de soja en Paraguay, 1997-2018

\begin{tabular}{ccc} 
Zafra & Área de siembra (has) & Producción comercial (ton) \\
\hline $1996-1997$ & 1050000 & 2771000 \\
$1997-1998$ & 1150000 & 2988201 \\
$1998-1999$ & 1200000 & 2980058 \\
$1999-2000$ & 1200000 & 2911423 \\
$2000-2001$ & 1350568 & 3502179 \\
$2001-2002$ & 1445365 & 3546674 \\
$2002-2003$ & 1550000 & 4518015 \\
$2003-2004$ & 1936623 & 3911415 \\
$2004-2005$ & 2009474 & 4040828 \\
$2005-2006$ & 2227487 & 3641186 \\
$2006-2007$ & 2429796 & 5581117 \\
$2007-2008$ & 2644856 & 5968085 \\
$2008-2009$ & 2524649 & 3647205 \\
$2009-2010$ & 2680182 & 6462429 \\
$2010-2011$ & 2870539 & 7128364 \\
$2011-2012$ & 2957408 & 4043039 \\
$2012-2013$ & 3157600 & 8202190 \\
$2013-2014$ & 3254982 & 8189542 \\
$2014-2015$ & 3264480 & 8153587 \\
$2015-2016$ & 3264480 & 9216937 \\
$2016-2017$ & 3388709 & 10336144 \\
$2017-2018$ & 3400000 & 10262575 \\
\hline & & \\
\hline
\end{tabular}

Fuente: Cámara Paraguaya de Exportadores y Comercializadores de Cereales y Oleaginosas, recuperado de http://capeco.org.py 
La fuerza impulsora detrás de ese crecimiento volátil del PIB es reducible (casi por completo) al auge de la producción de soja transgénica (véase cuadro 1), que representa aproximadamente 55 por ciento del valor de las exportaciones (Guereña, 2013), lo que ha convertido a Paraguay en el país con la economía más dependiente de la soja en el mundo (Ezquerro-Cañete, 2016a). Al respecto, el campo paraguayo se ha visto afectado por otros cambios más amplios en el régimen alimentario mundial, como la reestructuración neoliberal globalizada y el despliegue de cultivos transgénicos en América Latina desde mediados de la década de 1990 (véase Otero, 2012). En particular, la conversión de Paraguay en la llamada «República de la Soja» (es decir, en el régimen neoliberal de la soja del Cono Sur) ha llevado a una marcada transformación en el modo de producción agrícola, ocasionada por la adopción de cultivos genéticamente modificados, de agroquímicos y de técnicas de no-labranza (no till).

Mi argumento es que Paraguay ha sido testigo y ha experimentado todos los desarrollos contradictorios y todas las trampas del agroextractivismo. Esto incluye una mayor concentración de tenencias de tierra y la reducción del empleo, a medida que los trabajadores rurales se vuelven «excedentes» de los requisitos del capital de la agroindustria, así como una creciente dependencia de los agroquímicos que comprometen la calidad medioambiental y la salud humana. Al mismo tiempo, la «transgenización» de la soja en la agricultura paraguaya ha acelerado la expulsión forzada del campesinado. ${ }^{3}$ La inserción de Paraguay en la «República de la Soja», dentro del régimen neoliberal del Cono Sur, ha generado un nuevo sistema de desposesión impulsado por las nuevas prácticas agroindustriales

${ }^{3}$ Según Fogel (2019), Paraguay es el país más transgenizado del mundo, considerando la proporción de la superficie total destinada a este tipo de cultivo. 


\section{Arturo EzQuerro-CAÑETE}

asociadas con este régimen. La naturaleza débil, ausente o confabuladora del Estado paraguayo es fundamental para entender cómo el uso de químicas agroindustriales intensivas, dictadas por un capital altamente globalizado, ha reescrito la dinámica del proceso histórico de «acumulación por desposesión». En un trabajo anterior sugerí que este proceso podría específicamente, «acumulación por fumigación y desposesión» (Ezquerro-Cañete, 2016a). ${ }^{4}$ Esto es, el desplazamiento del campesinado de sus tierras, forzado por el uso intensivo de agrotóxicos, cuando los cultivos están ubicados cerca de los lugares donde viven los campesinos (es decir, la deriva de agroquímicos como un nuevo mecanismo de acumulación por desposesión medioambiental).

Los cambios económicos, políticos y distributivos asociados con la transición a la democracia, y la incorporación al régimen alimentario neoliberal, han realineado la estructura de las clases rurales en Paraguay. Dicha estructura incluye a la élite (ganaderos, sojeros, generales del ejército y acólitos políticos, quienes se adjudicaron grandes propiedades ilegalmente durante el régimen de Stroessner, bajo el disfraz de reforma agraria) y también al campesinado en sentido amplio (pequeños terratenientes, campesinos sin tierra y temporeros). ${ }^{5}$ El censo agrario de 2008 sugiere que las tenencias de 20 hectáreas o menos constituían 83.5 por ciento del número total de unidades agrícolas, pero representaban sólo 4 por ciento de la superficie de las tierras agrícolas del país (MAG, 2009). En el otro extremo, 4 mil 691 explotaciones (apenas 1.6 por ciento del total) controlaban 79 por ciento de todas las tierras agrícolas. De éstas, las 600 explotaciones

\footnotetext{
${ }^{4}$ Una versión en español puede encontrarse en un número anterior de esta misma revista (Ezquerro-Cañete, 2016b).

${ }^{5}$ Para análisis similares, véase Nickson (2010), Palau (2010) y Fogel (2015).
} 
más grandes (0.2 por ciento del total) controlaban 40.7 por ciento de la agricultura del país.

Estas cifras, según corroboran varios estudios, dan testimonio del hecho de que la distribución de las tierras agrícolas en Paraguay es una de las más desiguales, si no la más, del mundo. Por ejemplo, en 1991, el coeficiente Gini de Paraguay fue de 0.93, el más alto de los 133 países encuestados en el Informe de Desarrollo Mundial 2008 del Banco Mundial (2007); mientras que un informe más reciente de Oxfam reveló un coeficiente de Gini aún mayor de 0.94 (Guereña, 2013). Tal desigualdad no es un problema nuevo en Paraguay, ${ }^{6}$ pero, como se verá en la siguiente sección, la falta de programas de reforma agraria sostenidos, coordinados o significativos, y de programas de alivio de la pobreza rural, combinada con la promoción excesiva de las agroexportaciones, ha agravado aún más la situación en los últimos 20 años.

\section{Estructura de clases agrarias en Paraguay}

Concerneinte a la estructura de clases en Paraguay, pienso que sería útil enmarcar nuestro argumento en términos del autor marxista argentino

${ }^{6}$ El contexto histórico de la escandalosamente desigual distribución de tierra en Paraguay tiene un antecedente largo y tortuoso que se remonta a casi un siglo y medio. A diferencia de gran parte de América Latina, el desarrollo del sistema de haciendas paraguayo (es decir, una estructura agraria dual compuesta de latifundios o grandes haciendas, por un lado, y de minifundios o pequeñas granjas orientadas a la subsistencia, por el otro) no está primariamente arraigado en la colonización europea del siglo XVI (Kleinpenning, 1984). En cambio, la concentración de las tierras y la marginación del campesinado se basan en gran medida en la derrota de Paraguay en la Guerra de la Triple Alianza (1864-1870), por la cual se vendieron grandes extensiones de las tierras dominadas en su totalidad por el Estado a inversores extranjeros y a la élite paraguaya, como medio para pagar la deuda de guerra (Pastore, 1972; Riquelme, 2003). Esto estableció un sistema de tenencia de la tierra muy desigual que permanece prácticamente sin cambios hasta nuestros días. 


\section{Arturo Ezquerro-CAÑEte}

Claudio Katz (2007), quien categorizó primordialmente tres fuerzas sociales con capacidades e intereses distintos y contrapuestos en América Latina: a) las clases pobres rurales y urbanas y los grupos oprimidos, b) las clases dominantes internas, y c) el imperialismo.

Adoptar este marco analítico dentro del contexto paraguayo significa centrarse en el equilibrio inestable de las relaciones de poder entre: a) el campesinado, que es en gran medida el actor más importante del movimiento social en el país, b) la élite política y económica, no menos importante en referencia a la larga historia de la hegemonía del Partido Colorado, los grupos de propietarios y las organizaciones de agronegocios, y c) las dinámicas del capital (agro)extractivista y del imperialismo extractivista, particularmente en relación con el subimperialismo brasileño, es decir, la agencia y la función del Estado brasileño en su apoyo activo a las operaciones del capital agroextractivista en Paraguay.

\section{La oligarquía terrateniente}

Los grupos de terratenientes comprenden algunas de las élites más ricas e influyentes del país y ejercen una fuerte presencia de cabildeo dentro del Congreso, con representación en los principales partidos políticos. En términos generales, la oligarquía terrateniente se puede dividir en dos grupos principales: los ganaderos y los granjeros de la soja. Los ganaderos han sido durante mucho tiempo un poderoso grupo de interesados, al tratarse de uno de los principales beneficiarios del desigual sistema de tenencia de la tierra en Paraguay. Están organizados a través de la Asociación Rural del Paraguay (ARP), fundada en 1938 en respuesta a la amenaza de expropiación que había sido planteada por el efímero gobierno reformista del Partido Febrerista (1936-1937). 
La gran mayoría de las familias de altos ingresos residentes en Asunción posee una estancia (rancho ganadero), por lo que existe una considerable superposición entre los ganaderos y otras partes interesadas, incluido el Partido Colorado (Nickson, 2010). En respuesta a la escalada de invasiones de tierras tras el derrocamiento de Alfredo Stroessner, la ARP llevó a cabo una vociferante campaña mediática en favor de la propiedad privada, argumentando que las invasiones y expropiaciones de tierras ahuyentarían la inversión extranjera directa. Esto condujo a la disolución de la comisión para el desarrollo rural, llamada Consejo Nacional de Coordinación del Desarrollo Rural (Concoder) (Nickson, 2015).

Los productores de soja emergieron como un poderoso grupo de interesados durante la década de 1990. Ha habido un aumento espectacular del área de cultivo de la soja, con agricultores inmigrantes brasileños que han consolidado sus propiedades mediante la compra de tierras a pequeños agricultores paraguayos, a menudo empobrecidos. Los productores de soja están representados por la poderosa Asociación Paraguaya de Productores de Soja, Cereales y Oleaginosas (APS), que representa a 50 mil agricultores comerciales «brasiguayos» (véase más adelante), quienes controlan la mayor parte de la enorme producción de soja de Paraguay, y también por la Cámara de Exportadores de Cereales y Oleaginosas de Paraguay (Capeco). La mayoría de sus miembros son agricultores familiares de rango mediano, a menudo inmigrantes de segunda generación procedentes de Brasil, descendientes de europeos. Se sobrentiende que las grandes empresas transnacionales de la soja que operan en Paraguay no son miembros de Capeco (Nickson, 2010).

ARP, APS y Capeco son miembros de la Unión de Gremios de la Producción (UGP), una poderosa organización paraguas establecida en 2005 
para defender los intereses de los productores y de los exportadores de productos agrícolas. Tradicionalmente, estos grupos han podido bloquear la reforma tributaria y agraria, no sólo a través del cabildeo, sino mediante la amenaza de acciones directas en forma de «tractorazos» (grandes demostraciones disruptivas que movilizan a miles de agricultores para bloquear carreteras con tractores y maquinaria agrícola). Por ejemplo, a finales de 2003, la Coordinadora Agrícola de Paraguay (CAP) amenazó con un «tractorazo», lo cual sirvió para bloquear efectivamente los planes del gobierno de imponer un impuesto al valor agregado (IVA) a los productos agrícolas no procesados.

\section{El movimiento campesino}

En ausencia de un proletariado industrial significativo, el movimiento campesino ha sido durante mucho tiempo, con diferencia, el movimiento social más importante y más fuerte de los que han desafiado al Estado y a la élite política (Fogel, 2009). Sin embargo, tradicionalmente, este movimiento ha permanecido atomizado en diferentes organizaciones de movimientos sociales, que surgieron con rapidez a partir de la década de 1990, tras sufrir una severa represión durante todo el régimen de Stroessner. ${ }^{8}$ Hubo un momento excepcional de unidad y cohesión durante el periodo 1994-1997, cuando las cinco principales organizaciones campesinas nacionales de aquel periodo, incluyendo la Federación Nacional Campesina

\footnotetext{
${ }^{7}$ Su membresía incluye la Coordinadora Agrícola del Paraguay y la Federación de Cooperativas de Producción.

${ }^{8}$ En 1976, por ejemplo, el gobierno de Stroessner reprimió y desarticuló violentamente una tentativa de alianza entre estudiantes y campesinos, basada en un movimiento campesino apoyado por la Iglesia llamado Ligas Agrarias.
} 
(FNC), la Organización de Lucha por la Tierra (OLT), el Movimiento Campesino Paraguayo (MCP), la Organización Nacional Campesina (Onac) y la Unión Nacional de Campesinos (UNC), así como 22 organizaciones diferentes en los niveles regional, departamental y municipal, se aglutinaron mediante la creación de otra poderosa organización paraguas, llamada la Mesa Coordinadora Nacional de Organizaciones Campesinas (MCNOC).

El evento fundacional de la MCNOC fue una marcha de protesta masiva de una escala sin precedentes en el país, que tuvo lugar en Asunción el 15 de marzo de 1994, para exigir una reforma de la política agraria del gobierno. La marcha congregó unas 20 mil personas y se constituyó en la primera movilización nacional de organizaciones campesinas, que previamente habían articulado sus demandas sólo a escala local o regional. Cada año a partir de entonces las organizaciones campesinas han celebrado una marcha de protesta masiva en la capital del Estado para presentar sus demandas, haciendo una demostración pública de su fuerza multitudinaria (Levy, 2013).

Aunque la demanda central de las diversas organizaciones campesinas es básicamente la misma (reforma agraria redistributiva), el movimiento está plagado de luchas internas y divisiones. Como resultado, el movimiento se ha fragmentado en diferentes organizaciones de movimientos sociales que, a veces, han propuesto distintos proyectos y estrategias, pero que en momentos puntuales se han unido para constituir su propio gobierno. En 1998, las rivalidades de liderazgo entre la FNC y la OLT ocasionaron una división dentro de la MCNOC (Piñeiro, 2004). De esa manera, puede decirse que la ausencia de un grupo unitario, que represente al campesinado, 


\section{Arturo Ezquerro-CAÑEte}

tiene más que ver con las rivalidades personales y la competencia por los recursos y el apoyo de masas entre sus líderes que por diferencias ideológicas y programáticas. Sin embargo, también es cierto que coinciden con divisiones más sustantivas y refuerzan las rivalidades personales. Las diferencias regionales en las condiciones políticas y en la estructura de tenencia de la tierra fomentan el uso de diferentes tácticas por los líderes campesinos. Estas diferencias se ven agravadas por las diferentes estructuras de base que poseen las organizaciones campesinas (Setrini, 2011:384-385).

La orientación nacionalista se ha dejado ver durante bastante tiempo dentro de los movimientos campesinos. Beverly Nagel explica que esto es en parte una consecuencia de la represión sufrida por las organizaciones campesinas durante el régimen de Stroessner: «Como la crítica de clase no podía ser expresada, el reclamo nacionalista proporcionaba el único espacio real para las objeciones» (Nagel, 1999:157). Tal retórica nacionalista adquiere una dimensión especial por la peculiaridad lingüística del país: Paraguay es la única nación de América Latina en la que la mayoría de la población habla una sola lengua indígena (el guaraní) aunque no se identifica políticamente como indígena. ${ }^{9}$ Según el censo de 2002, el guaraní es preferido por 59 por ciento de los hogares en comparación con 35.8 por ciento que prefiere el castellano (DGEEC, 2004). En las zonas rurales el guaraní sigue siendo, con mucho, el idioma predominante, preferido por 82.5 por ciento de la población. Por ende, ha habido una tendencia (no exenta de discontinuidades o de contradicciones) a que la composición

\footnotetext{
${ }^{9}$ Paraguay tiene una población mestiza en gran parte homogénea. Según el censo de 2012 la población indígena ascendía a 117 mil 150 personas (DGEEC, 2013), equivalente a aproximadamente 2 por ciento de la población nacional.
} 
etnolingüística guaraní de los movimientos campesinos paraguayos sea considerada un análogo de clase (Petras, 1997).

Este discurso nacionalista es particularmente evidente cerca de la frontera con Brasil, donde los paraguayos nativos se sienten perjudicados por su desposesión, como consecuencia de la ocupación de las tierras por brasileños y «brasiguayos»..$^{10}$ Los argumentos y la retórica utilizados son decididamente nacionalistas, con similitudes obvias respecto a las invasiones brasileñas de tiempos pasados. En un conmovedor ejemplo de la creciente animosidad hacia los «brasiguayos», citada en los periódicos nacionales en 2008, los campesinos quemaron la bandera brasileña en una celebración del día de la independencia en Curupayty, en el departamento de San Pedro (ABC Color, 2008).

\section{Subimperialismo brasileño}

Según exponen acertadamente Veltmeyer y Petras, el capital extractivo se percibe sobre todo como «corporaciones multinacionales, portadoras de capital en forma de inversión extranjera directa» (2014:28). Por otro lado, el imperialismo extractivista se refiere «al Estado en el ejercicio y la proyección de sus diversos poderes en apoyo de este capital» (Veltmeyer y Petras, 2014:28). ${ }^{11}$ Sin embargo, en el caso paraguayo es preciso hacer una

${ }^{10} \mathrm{El}$ uso del término «brasiguayos» ha sido objeto de una crítica particular por la dicotomía que lleva implícita entre agricultores brasileños ricos dedicados a la producción de soja por un lado, y campesinos paraguayos empobrecidos y marginados por el otro (Blanc, 2015). En realidad, «la mayoría de los inmigrantes brasileños en Paraguay son pequeños agricultores que, como muchos de sus vecinos paraguayos empobrecidos, se han enfrentado a una marginación constante» (Blanc, 2015:145).

" Para un debate más completo sobre la relación íntima entre el imperialismo (extractivista) y el capitalismo, véase Veltmeyer y Petras (2015). 


\section{Arturo Ezquerro-CAÑEte}

distinción adicional relacionada con un renovado interés en el concepto de subimperialismo propuesto por Marini (1972), que redirige la atención a la alianza geopolítica entre el Estado brasileño y los intereses de los agronegocios privados (véase Vuyk, 2014; Zibechi, 2014; Oliveira, 2016). El complejo sojero del país tiene un carácter claramente «translatino», debido a la gran afluencia de capital extranjero (en especial brasileño), que controla 64 por ciento de la tierra cultivada con soja en los cuatro departamentos sojeros más importantes del país: Alto Paraná, Canindeyú, Caaguazú e Itapúa (Galeano, 2012).

Este proceso de «extranjerización» comenzó en la década de 1970 con la liberación de tierras estatales para la compra privada (Nickson, 1981), pero se ha acelerado en las últimas dos décadas a medida que las tierras paraguayas se integran cada vez más en las fronteras agrícolas en expansión de Brasil y, en un grado mucho menor, Argentina (Galeano, 2012). Aunque aún no es un inversionista directo en la tierra, el gobierno brasileño brinda un apoyo significativo a los inversores brasileños: primero, monitorea acuerdos de inversión para adquirir o arrendar tierras (a través de la embajada brasileña), y segundo, brinda asistencia técnica (por medio de agencias estatales brasileñas) a empresas ganaderas (Galeano, 2012). Además, frente a la agitación cada vez más militante de los campesinos sin tierra en Paraguay, en su lucha por la redistribución de las granjas de soja de propiedad brasileña, el gobierno brasileño emitió fuertes advertencias y amenazó con sanciones contra tales acciones. Por ejemplo, a principios de octubre de 2008, el presidente brasileño Lula firmó el Decreto 6.592, que reglamenta la Movilización Nacional y crea el Sistema Nacional de Movilización (Sinamob) dedicado a confrontar la «agresión extranjera». El primer artículo del decreto define la agresión extranjera: «Amenazas o actos lesivos a la soberanía nacional, 
la integridad territorial, al pueblo brasileño o a las instituciones nacionales son parámetros, aun cuando no signifiquen invasión al territorio nacional» (citado en Última Hora, 2008, énfasis añadido). En otras palabras, cualquier expropiación de tierras de propiedad brasileña en Paraguay podría usarse como pretexto para la acción militar brasileña contra Paraguay. En ese sentido, el interés brasileño (subimperialista), es decir, la intervención del Estado brasileño en apoyo de sus nacionales en el conflicto por la tierra, ha pasado a ser un obstáculo permanente de cara a la redistribución de la tierra, en concreto en el caso de Ñacunday (Fogel, 2013).

\section{La lucha de clases en una era de transición prolongada hacia la democracia (1989-2008)}

La transición del régimen de Stroessner a una democracia electoral de tinte conservador estuvo acompañada de una creciente movilización de campesinos. Los flujos y reflujos de la lucha de clases por la tierra a lo largo de la prolongada transición a la democracia se muestran en el cuadro 2. A simple vista, tres años sobresalen en términos de conflictos y arrestos: 1989, que con la caída del régimen de Stroessner abrió la puerta a la expresión del descontento rural, manifestado principalmente mediante una ola de ocupaciones de tierras a lo largo del año siguiente; 1999, que marcó el llamado «marzo paraguayo»; y 2004, que representa el pico en el número de ocupaciones de tierras, desalojos y arrestos de campesinos. La siguiente sección proporciona una breve descripción cronológica de los picos y valles de la acción colectiva y de la represión estatal asociada, así como de la criminalización de las protestas campesinas. 
Arturo EzQuerro-CAÑETE

\section{Cuadro 2}

Movilizaciones campesinas 1990-2007

\begin{tabular}{lccccc} 
Año & Conflictos & Ocupaciones & Desalojos & Detenciones & Manifestaciones \\
\hline 1990 & 99 & 49 & 51 & 820 & 34 \\
1991 & 66 & 17 & 23 & 566 & 19 \\
1992 & 50 & 16 & 16 & 120 & 15 \\
1993 & 46 & 14 & 17 & 128 & 18 \\
1994 & 57 & 26 & 24 & 411 & 60 \\
1995 & 49 & 23 & 25 & 359 & 37 \\
1996 & 54 & 20 & 27 & 553 & 39 \\
1997 & 43 & 15 & 13 & 137 & 15 \\
1998 & 28 & 14 & 11 & 429 & 17 \\
1999 & 52 & 31 & 20 & 1048 & 54 \\
2000 & 47 & 19 & 12 & 531 & 34 \\
2001 & 42 & 17 & 24 & 260 & 73 \\
2002 & 28 & 16 & 14 & 161 & 49 \\
2003 & 51 & 30 & 19 & 339 & 41 \\
2004 & 149 & 75 & 74 & 1400 & 30 \\
2005 & 34 & 7 & 7 & 34 & 36 \\
2006 & 45 & 24 & - & 50 & 69 \\
2007 & 40 & 20 & 9 & 2 & 45 \\
\hline
\end{tabular}

Fuente: Centro de Documentación y Estudios (2007).

1989-1990: ola de ocupaciones

El derrocamiento de Stroessner estimuló una ola de ocupaciones de tierras y un florecimiento de la organización campesina. A mediados de la década 
de 1990, aproximadamente 19 mil familias habían reclamado tierras que totalizaban más de 360 mil hectáreas (Nagel, 1999). La ola de ocupaciones de tierra fue seguida por un contraataque de la clase terrateniente; las fuerzas paramilitares y luego el ejército intervinieron para desalojar a muchas familias. La posición del gobierno se resumió en la siguiente cita del presidente Rodríguez (1989-1993), quien declaró: «Hemos resuelto declarar una guerra total contra los invasores de la propiedad privada (...)Aquellos que hacen las declaraciones de manera honesta y con justicia recibirán una respuesta positiva del gobierno, pero a los invasores, guerra total, guerra total» (ABC Color, 28 de marzo de 1990, citado en Nagel, 1999:166). En 1990 hubo 51 desalojos de tierras y 820 campesinos fueron arrestados. El patrón de invasión y desalojo ha continuado bajo sucesivos gobiernos del Partido Colorado. A mediados de la década de 1990, el nuevo gobierno desplegó las Fuerzas Armadas para sofocar las ocupaciones y emprendió una campaña para desalojar a la fuerza a los ocupantes y destruir sus chozas y cultivos (Nagel, 1999). El Comité Coordinador de los Derechos Humanos en Paraguay (Codehupy, 2007) informó del asesinato de 77 líderes rurales en el contexto de la lucha por la tierra entre 1989 y 2005.

\section{9: «marzo paraguayo»}

En 1999, en lo que se conoce como «la masacre del marzo paraguayo», las protestas campesinas regulares estaban programadas para marzo, cuando el asesinato del vicepresidente Luis Argaña desencadenó una crisis política. A cambio de la condonación de los préstamos del sector público a sus miembros, las organizaciones campesinas nacionales se unieron a los 
líderes estudiantiles que se oponían al intento de golpe de Estado por parte del general Lino Oviedo. Los líderes campesinos (junto con los estudiantiles) pudieron movilizar un número lo suficientemente grande como para defender al gobierno constitucional. Sin embargo, como expresa Setrini,

la naturaleza de esta acción fue claramente clientelar: el apoyo político al gobierno de turno a cambio de la condonación de la deuda. Más aún, los líderes garantizaron beneficios materiales para sus seguidores, traicionando las preferencias políticas de sus bases, entre los cuales se encontraban muchos partidarios de Oviedo (Setrini, 2011:383; véase también Hetherington, 2011:47-56).

\section{La década de 2000: de la movilización antineoliberal a la lucha de clases en curso}

En el nuevo milenio, la lucha de clases adquirió una vez más un papel diferente bajo los condicionantes de varios cambios definitorios en la economía global. Junto a la cuestión no resuelta de la tierra, la lucha de clases en este periodo tomó la forma de levantamientos y de una resistencia generalizada contra la agenda neoliberal (que conllevaba una reforma estructural en las políticas públicas macroeconómicas) y, más tarde, contra las actividades depredadoras asociadas con las operaciones del capital agroextractivista.

La primera lucha se centró, en 2002, en una ola de resistencia antineoliberal sin precedentes contra las políticas gubernamentales de privatización de las empresas estatales y de un paquete de políticas de austeridad económica, dictadas por el presidente colorado Luis González Macchi (1999-2003), respaldado por el Fondo Monetario Internacional (FMI). 
Vociferantes en su oposición a la participación del sector privado en los servicios públicos y en su defensa del acuerdo institucional existente para la provisión de suministro de agua, electricidad y telecomunicaciones, la FNC y la MCNOC se unificaron nuevamente en 2002 y proporcionaron la columna vertebral del Congreso Democrático del Pueblo (CDP). Éste comprendía una amplia coalición de los partidos políticos de izquierda y más de 60 grupos campesinos, sindicales y comunitarios en oposición al programa de privatización impuesto por el FMI.

Entre junio y septiembre de 2002 el CDP organizó marchas a gran escala en Asunción que obligaron al gobierno a hacer un cambio en la privatización de tres empresas estatales (servicios de agua, de electricidad y de ferrocarriles). ${ }^{12}$ Tras una protesta y un conflicto generalizados, el gobierno se vio obligado a aceptar toda la demanda del CDP, incluyendo la suspensión indefinida de todos los planes de privatización contenidos en el paquete del FMI. ${ }^{13}$ Nuevas manifestaciones también condujeron a la derogación de la legislación gubernamental que buscaba introducir más medidas de «ajuste del cinturón», incluido un aumento de los precios en los servicios públicos. Ante tal resurrección organizativa de la sociedad civil estaba claro que cualquier gobierno entrante tendría que enfrentarse a esta oposición profundamente arraigada en la lucha contra las reformas neoliberales (Palau, 2002; Lambert, 2005; Nickson, 2010; Setrini, 2011).

${ }^{12}$ Irónicamente, al impedir la privatización, las organizaciones campesinas también prestaron su apoyo a los elementos rentistas del Estado, cuyos intereses radican en el descarrilamiento permanente de la reforma del sector público en Paraguay (Setrini, 2011).

${ }^{13}$ Con un Congreso liderado por la oposición, con el inicio de un juicio político contra el presidente, con las elecciones generales un año más tarde y con el apoyo del general Oviedo a otro potencial intento de golpe de Estado desde el extranjero, los legisladores del Partido Colorado negociaron la derogación del programa de privatización con los líderes sindicales y los campesinos, a cambio del desmantelamiento del movimiento de protesta (Setrini, 2011). 


\section{La lucha por la tierra en curso}

Tras varias promesas de reforma agraria incumplidas por el gobierno, junto a su inacción ante la creciente crisis, la lucha se recrudeció a mediados de la década de 2000. ${ }^{14}$ Como se puede observar en el cuadro 2, el número de ocupaciones de tierras alcanzó un pico en el año 2004: hubo 75 ocupaciones de tierras, 74 desalojos y mil 400 arrestos. La paciencia de los dos principales sindicatos campesinos finalmente se agotó. En septiembre de 2004, la MCNOC y la FNC organizaron una serie de ocupaciones y protestas masivas en el nivel nacional para exigir una reforma agraria inmediata (Lambert, 2005). De manera muy parecida a la proclama anterior de Rodríguez, el presidente Nicanor Duarte Frutos (2003-2008), en una reunión que tuvo con los grandes terratenientes y refiriéndose a los campesinos que ocupaban propiedades, declaró: «Los vamos a traer por las orejas, y a aquellos que tengan orejas pequeñas los traeremos por el pelo» (citado en González Bozzolasco, 2005). A principios de diciembre la FNC reanudó las invasiones de tierras.

\section{La lucha de clases en la frontera extractiva}

La segunda forma principal de la lucha de clases en ese momento tenía que ver con la resistencia contra la dinámica del agroextractivismo. Como lo expresé con anterioridad, sostengo que Paraguay ha sido testigo y ha experimentado todos los desarrollos contradictorios y las trampas del

${ }^{14}$ Luego de una serie de protestas campesinas, el gobierno de González Macchi (1999-2003) asignó fondos para proyectos agrícolas a la FNC y la MCNOC. No obstante, los fondos se otorgaron sin ningún tipo de control administrativo, lo que provocó acusaciones inmediatas de que el gobierno estaba tratando de «sobornar» al liderazgo campesino (Lambert, 2005). 
agroextractivismo, incluyendo la oligarquía terrateniente, la reducción del empleo y la aceleración de las expulsiones forzadas del campesinado. Los trabajadores rurales son considerados «excedentes» de los requisitos del capital de la agroindustria y existe una creciente dependencia de agroquímicos que comprometen la calidad ambiental y la salud humana. ${ }^{15}$

Con respecto a la cuestión de los agroquímicos, la «sojización transgénica» de la tierra en Paraguay ha generado un nuevo régimen de desposesión impulsado por nuevas prácticas agroindustriales asociadas con este modelo — «acumulación por fumigación y desposesión» (Ezquerro-Cañete, 2016a). Una vez más, la naturaleza débil, ausente o confabuladora del Estado paraguayo es fundamental para entender cómo el uso intensivo de pesticidas agroindustriales, dentro de un sistema capitalista altamente globalizado, ha reescrito la dinámica del proceso histórico, desatando poderosas fuerzas de resistencia. Tal vez el caso que generó el mayor escándalo público contra el sector sojero fue la muerte por envenenamiento en 2003 de Silvino Talavera, un niño de once años que fue rociado por un fumigador en su camino de la escuela a casa (Hetherington, 2013) $\cdot{ }^{16}$ Hijo de un miembro de la Coordinadora Nacional de Organización de Mujeres Trabajadoras, Rurales e Indígenas (Conamuri), la muerte de Silvino provocó una amplia movilización contra el uso indiscriminado de agroquímicos (véase Palau y Kretschmer, 2004; Viveros, 2012).

${ }^{15}$ La naturaleza excluyente y socialmente problemática de lo que podríamos llamar la «sojización transgénica» de la agricultura paraguaya, se analiza con mayor detalle en Fogel y Riquelme (2005), Palau et al. (2007), Guereña (2013), Hetherington (2013), Riquelme y Vera (2013), Elgert (2016) y Ezquerro-Cañete (2016a).

${ }^{16}$ Mientras se rumoreaba que otros casos habían ocurrido en la totalidad del campo paraguayo, éste fue el primero en el que un equipo de activistas y de abogados lograron obtener evidencia médica, a través de los análisis de la sangre del niño realizados en Buenos Aires, de que los pesticidas fueron la causa de su muerte (Hetherington, 2014). 


\section{Arturo EZquerro-CAÑETE}

Tales fuerzas de desarrollo y cambio conforman el contexto para abordar la siguiente sección de este trabajo: la dinámica de la lucha de clases durante «el ascenso y la caída» de Fernando Lugo. Al examinar la distribución previa del poder en la sociedad y dentro del Estado, así como las constelaciones de actores estatales y sociales y sus alianzas, acciones y estrategias, podemos comenzar a identificar la naturaleza del problema político que obstaculiza cualquier intento de reforma agraria redistributiva en Paraguay. El contexto histórico-político incluye el legado de un Estado predatorio, el carácter cambiante del capitalismo agroextractivo contemporáneo (en específico en relación con los intereses subimperiales del capital brasileño) y la creciente violencia, corrupción y disputa por la tierra. Es en este contexto en el que debemos situar nuestro análisis de la economía política y de la dinámica del cambio social, durante los casi cuatro años del gobierno de Lugo (de agosto 2008 a junio 2012).

\section{El interregno de Lugo (2008-2012) $)^{17}$}

Fernando Lugo, obispo católico y persona independiente sin carrera previa como político, asumió la presidencia en agosto de 2008 como líder de una coalición electoral fragmentada e ideológicamente dividida, la Alianza Patriótica para el Cambio. Según señaló Andrew Nickson (2008), la victoria de Lugo implicó tres «primicias». Fue la primera vez en más de sesenta años que un candidato no perteneciente al Partido Colorado gobernara el país. Sorprendentemente, esto solapó el hecho de que también se trataba

${ }^{17}$ Gran parte de la siguiente sección proviene de Ezquerro-Cañete y Fogel (2017); para una traducción en español, véase Ezquerro-Cañete y Fogel (2018). 
de la primera vez que se hacía una entrega pacífica de poder de un partido político a otro en la historia de Paraguay. Asimismo, fue la primera vez que ocurría en el mundo que una persona pasase directamente del sacerdocio a la presidencia. ${ }^{18}$

Al mismo tiempo, el ascenso de Lugo a la presidencia aconteció dentro de una década de significativo, aunque desigual, cambio social y político hacia la izquierda en gran parte de América Latina (Petras y Veltmeyer, 2009). Sin embargo, Lugo estaba constreñido por su dependencia de los socios de la coalición de centro-derecha, lo que hacía que su elección fuera más ambigua y «algo así como una farsa» (Hetherington, 2011:227). Dejando de lado algunos intentos iniciales de presentar la elección de Lugo como «otra pluma en el sombrero» para el «socialismo del siglo XXI» (por ejemplo, O’Shaughnessy y Ruiz Díaz, 2009), varios observadores más sopesados se apresuraron a desvelar las significativas restricciones estructurales e institucionales y demás limitaciones con las que se tendría que enfrentar la administración de Lugo desde el comienzo.

Nickson (2008), por ejemplo, estimó equivocadas las comparaciones del régimen de Lugo con el «socialismo del siglo XXI» y advirtió que, a pesar de ser «influenciado por la teología de la liberación», Lugo «había tenido grandes dificultades para presentarse como un candidato de «centro-izquierda> y para ser visto como un radical afín al amplio movimiento populista que se iba extendiendo por el resto de América Latina». En una línea similar, Kregg Hetherington (2011:227) sugirió que «un paralelo más instructivo en la historia reciente no es la victoria de Chávez en Venezuela,

${ }^{18}$ «En una llamativa marcha atrás, el 30 de julio de 2008, el Vaticano le concedió a Lugo la primera bula papal para que un obispo católico volviera a su previo estatus laico» (Nickson, 2009:148n10). 


\section{Arturo EzQuerro-CAÑETE}

sino la victoria de Vicente Fox, en 2000, sobre el Partido Revolucionario Institucional (PRI) de México, que había sostenido el poder bajo diferentes nombres desde 1928». En su estudio del «post-neoliberalismo» en América Latina, Yates y Bakker (2014) van más allá y ubican la administración de Lugo dentro de la ideología política llamada «neoliberalismo incluyente» y «nacionalismo», aunque no proporcionan ningún análisis para fundamentar su reclamo. Quizá la interpretación más convincente pueda encontrarse en la creciente literatura que ilustra cómo la administración de Lugo se adaptó ampliamente al régimen gramsciano, conocido como «cesarismo» (González Bozzolasco, 2009; Bourscheid, 2016; Ezquerro-Cañete y Fogel, 2017). Esto consiste en una «solución arbitraria, confiada a una gran personalidad, de una situación histórico-política caracterizada por un equilibrio de fuerzas de perspectiva catastrófica» (Gramsci, 1973:219).

En 1994 Lugo había sido ordenado por el papa Juan Pablo II como el obispo de San Pedro, el departamento más pobre de Paraguay y una diócesis llena de conflictos sociales (Abente Brun, 2009). En San Pedro, Lugo comenzó un ascenso gradual, trabajando junto a los campesinos y haciendo campaña con ellos en sus luchas por la tierra (Nickson, 2009). Fue elevado a la arena política en marzo de 2006, cuando encabezó un mitin y una marcha de 40 mil personas en Asunción para protestar contra el plan inconstitucional de Nicanor Duarte Frutos, presidente en ejercicio, para buscar su reelección (Nickson, 2009). El plan Duarte fue derrotado, gracias al papel catalizador de Lugo al encabezar aquella multitudinaria marcha de los movimientos sociales del país, en marzo de 2006. Tal era la desilusión del pueblo con los políticos que Lugo fue inmediatamente catapultado a la arena política nacional; más de 100 mil personas firmaron una petición en la que le pedían que abandonara el sacerdocio y que 
presentara su nombre como candidato presidencial. ${ }^{19}$ Más tarde, ese año, Lugo ayudó a crear un nuevo movimiento político, Partido Popular Tekojojá (que significa «vida e igualdad» en guaraní). El 25 de diciembre de 2006 Lugo anunció que se presentaría a las elecciones presidenciales de 2008 como candidato de consenso de una oposición fracturada (Nickson, 2009).

Esto llevó a la creación de la APC, una organización electoral formada por un amplio espectro de movimientos sociales y sindicatos y de una miríada de pequeños partidos de izquierda, fuertes en militancia, pero electoralmente débiles por su cultura política basada en el mecenazgo de Paraguay. La coalición incluía a demócratas cristianos, a socialistas de diversos matices y a «desafectados» radicales del Partido Colorado. Crucial para su éxito (pero también para su desaparición) fue una alianza estratégica con el antiguo Partido Liberal (PLRA), que aceptó apoyar la candidatura de Lugo a cambio del boleto de la vicepresidencia (Nickson, 2009). En la campaña presidencial de 2008 Lugo se enfrentó a la candidata del Partido Colorado, Blanca Ovelar. Lugo ofreció vagas promesas sobre reformas socioeconómicas de largo alcance para abordar los problemas crónicos de la pobreza, la desigualdad y la corrupción en Paraguay. Fundamentalmente, la reforma agraria fue colocada de nuevo en la agenda política, un tema de especial importancia en un país con la mayor desigualdad de tierras en toda América Latina y donde más de 40 por ciento de la población vive en el campo.

Una vez en la presidencia Lugo hizo algunos movimientos tímidos hacia una reforma social y económica de carácter progresista. Amplió una serie de políticas sociales a favor de las familias en extrema pobreza (Tekoporã), así como a favor de la prevención de la explotación laboral infantil

${ }^{19} \mathrm{La}$ Constitución paraguaya no permite que un sacerdote pueda ser elegido presidente. 


\section{Arturo EzQuerro-CAÑEte}

(Abrazo) y del apoyo a los estudiantes (complemento nutricional, kits escolares) y a los grupos indígenas (desarrollo comunitario). Renegoció con éxito una mejora parcial del Tratado de Itaipú de 1973 con Brasil, que durante mucho tiempo había sido una fuente de controversia en Paraguay. ${ }^{20}$ Sin embargo, la promesa electoral central de Lugo (la reforma agraria) quedó en punto muerto. Según indicó Peter Lambert (2011:185-186):

La incapacidad del gobierno para implementar su programa de reforma agraria fue consecuencia no tanto de una falta de voluntad o incluso de recursos, sino de la existencia de una oposición coordinada, dotada de recursos y poderosa. Los grupos de propietarios (...) comprenden algunas de las élites más ricas e influyentes del país, y disfrutan de una fuerte presencia de cabildeo, con representación en todos los principales partidos políticos.

${ }^{20}$ Aunque cada país posee una participación igual (50 por ciento) de la energía producida, el tratado obliga a Paraguay a vender a Brasil toda la electricidad no utilizada a un precio de costo establecido, en lugar de poder venderla a terceros a precio de mercado. En la práctica Paraguay apenas utiliza 7 por ciento de la producción de energía eléctrica y, por lo tanto, vende el resto de su parte a Brasil. Aunque Paraguay recibe una tarifa de «compensación» de \$120 millones por año, se ha argumentado durante mucho tiempo que éste es un tratado «escandalosamente injusto», por el cual Paraguay otorga a Brasil un subsidio de aproximadamente 20 por ciento del uso nacional de electricidad, valorado en $\$ 3$ mil millones por año (Nickson, 2009). Después de reiteradas negativas por parte de Brasil para renegociar las condiciones del acuerdo vigente hasta 2023, la presión constante de Lugo, incluidas algunas amenazas veladas de llevar el asunto a la Corte Internacional de Justicia, hizo que se alcanzara un nuevo acuerdo en julio de 2009. Brasil prometió lo siguiente: triplicar las regalías de «compensación» a Paraguay ( $\$ 360$ millones por año), finalizar la construcción de una subestación y de una línea de transmisión hasta Asunción, aceptar auditorías y transparencia, permitir que Paraguay comience a vender gradualmente electricidad a Brasil a precio de mercado (pero no a otros países) y admitir que la gestión sea compartida por los dos países (Comisión de Entes Binacionales Hidroeléctricos 2009). Esto se interpretó en Paraguay como una gran victoria, ya que los ingresos anuales adicionales podrían duplicar la inversión pública del gobierno central y financiar grandes programas de reducción de la pobreza y de gasto social. Sin embargo, las dos cámaras de la legislatura brasileña no aprobaron el acuerdo hasta mayo de 2011 (Lambert, 2011). 
La oposición por parte del Partido Colorado y de la Unión Nacional de Ciudadanos Éticos (Unace), junto con las facciones disidentes dentro de la APC, consiguió bloquear la legislación clave relativa a la agenda de reformas de Lugo. El 4 de junio de 2009 el Congreso votó para posponer aún más un impuesto a la renta personal, reduciendo de ese modo una fuente de ingresos clave (alrededor de $\$ 160$ millones), mientras que el mismo día se negó a aprobar un acuerdo entre la central hidroeléctrica Itaipú Binacional y la Coordinadora Ejecutiva para la Reforma Agraria (Cepra) el cual financiaría nuevos asentamientos para las familias sin tierra. En la misma sesión, y en contra de los deseos del ministro de finanzas Dionisio Borda, también se aumentaron las pensiones estatales y se duplicaron los salarios de los gobernadores departamentales y de los miembros de la Comisión Electoral Nacional, a un costo combinado de $\$ 118$ millones. Dicho de otra manera, el Congreso votó para bloquear los flujos de financiamiento vitales, mientras que al mismo tiempo votó para aumentar el gasto, algo que inevitablemente conduciría a un déficit insostenible. Así, la capacidad del Instituto Nacional de Desarrollo Rural y de la Tierra (Indert) para ayudar a los campesinos sin tierra siguió siendo muy restringida, por limitaciones presupuestarias y por el requerimiento de compensar a los propietarios de tierras expropiadas a precio de mercado (Nickson, 2015).

En el ámbito de las agroexportaciones, el «giro a la izquierda» en Paraguay no coincidió con el cambio regional hacia el neodesarrollo (o «neoextractivismo progresista»). En marcado contraste con las políticas neodesarrollistas implementadas, por ejemplo, en Argentina bajo los regímenes Kirchner, donde se redistribuyeron parte de las rentas producidas al poner un impuesto de 35 por ciento sobre la soja (véase Lapegna, 2017), los intentos de Lugo de aprobar una ley para introducir un impuesto de 6 por 


\section{Arturo Ezquerro-CAÑEte}

ciento sobre las exportaciones de cereales no procesados (soja, maíz y colza) fueron rechazados reiteradamente por el Congreso. Como resultado, la administración de Lugo no pudo mover a Paraguay más allá de las políticas fundamentalistas de libre mercado y los impuestos a la agricultura comercial se mantuvieron en niveles irrisorios (el monto neto en 2011 fue de sólo \$13 millones, equivalente a 0.5 por ciento de los ingresos fiscales totales).

A pesar de las crecientes demandas de las organizaciones de la sociedad civil, el gobierno de Fernando Lugo no hizo nada para recuperar las tierras adjudicadas ilegalmente por IBR e Indert, lo que podría haber proporcionado una base para la redistribución a los agricultores sin tierra (Nickson, 2015). Peor aún es el hecho de que Lugo fue incapaz de detener la transferencia ilegal de tierras, que continuó durante toda su presidencia: en septiembre de 2011, Alberto Antebi Duarte (hijo del segundo terrateniente más rico de Paraguay, Roberto Antebi) recibió 4 mil hectáreas por este medio gracias a alta corrupción en Indert (Nickson, 2012).

La lentitud de la reforma durante la administración de Lugo llevó a un aumento en las ocupaciones de tierras, a un discurso cada vez más militante entre organizaciones campesinas y a choques con guardias de seguridad armados, a menudo brasileños (...) A medida que el proyecto de reforma agraria de Lugo se estancaba, el conflicto social se hacía cada vez más probable (Lambert, 2011:186).

El 15 de junio de 2012, 11 ocupantes ilegales y seis policías murieron en un tiroteo durante una operación de seguridad fallida por 324 policías para expulsar a 60 miembros de la organización campesina Movimiento por 
la Recuperación Campesina de Canindeyú (MRCC), que habían ocupado tierras cerca de Curuguaty. La tragedia fue el peor incidente de violencia política durante décadas, por lo que encendió las críticas de los movimientos campesinos y de los líderes de la oposición, aunque por razones muy diferentes. Tuvo lugar en una sección de 2 mil hectáreas de propiedad en Marina Kue (Departamento de Canindeyú), que fue obtenida espuriamente durante la era Stroessner por Blas Riquelme, un corrupto hombre de negocios y exsenador del Partido Colorado, bajo el disfraz de reforma agraria (Fogel, 2012).

El 11 de julio de 2016, un tribunal paraguayo condenó a 11 campesinos (ocho hombres y tres mujeres) por los asesinatos de los seis policías durante la masacre de Curuguaty. Rubén Villalba, quien fue identificado como el cabecilla de los ocupantes ilegales, fue condenado a 30 años de prisión. Luis Olmedo, considerado como el principal coautor del crimen, fue condenado a 20 años. Y otros dos hombres, Arnaldo Quintana y Néstor Castro, fueron condenados a 18 años cada uno por el mismo cargo. Otros siete campesinos recibieron sentencias de entre cuatro y seis años por asociación delictiva e invasión de propiedad privada (LAWR, 2016). Las dudas sobre la falta de imparcialidad e independencia en las investigaciones de los acontecimientos de Curuguaty se recogen en un comunicado de prensa del Comisionado de las Naciones Unidas para los Derechos Humanos, Zeid Ra’ad Al Hussein:

La condena de once campesinos en el caso Curuguaty, tras un juicio que presuntamente no respetó las garantías judiciales, es algo profundamente perturbador (...) [También es preocupante] el hecho de que, hasta ahora, las muertes de los once campesinos asesinados en el mismo incidente no hayan 


\section{Arturo Ezquerro-CAÑEte}

sido investigadas por las autoridades paraguayas, ni existan denuncias de que algunos de ellos fueron ejecutados sumariamente después de ser sometidos a tortura y a otras violaciones de los derechos humanos. ${ }^{21}$

La versión oficial de lo sucedido dice que los ocupantes ilegales habían disparado contra la policía primero, pero esta versión fue inequívocamente impugnada por organizaciones de activistas y de los derechos humanos (por ejemplo, Codehupy, 2012; PEICC, 2012). El modo como se realizaron las investigaciones siembra muchas dudas, debido a «denuncias de graves irregularidades en las actuaciones del Ministerio Público, de la judicatura y de las fuerzas de seguridad, con relación al operativo policial en Curuguaty, en junio de 2012» (conclusiones del Comité de Derechos Humanos 2013, en Paraguay). También existen acusaciones sobre la participación de tiradores ocultos, presuntamente contratados por los terratenientes para desencadenar una crisis política con el fin de expulsar a Lugo de su cargo. En tal clima de sospecha abundan las teorías de la conspiración. ${ }^{22}$

Inmediatamente después de la masacre de Curuguaty, un grupo dispar de fuerzas sociales conservadoras vio su oportunidad y convergió en torno al juicio político y a la destitución de Lugo. Las acusaciones de negligencia, ineptitud e incapacidad para actuar de manera decisiva,

${ }^{21}$ https://z-upload.facebook.com/watch/live/?v=10155997320837968\&ref=watch_permalink ${ }^{22}$ Según el examen independiente de imágenes de audio, realizado por expertos españoles en balística, se demostró que los policías fueron asesinados por fuego automático, algo incompatible con los viejos y rudimentarios rifles de caza que les fueron incautados a los okupas. La presencia de mujeres y niños sugirió que dichos okupas no pensaban actuar con violencia. Muchos llegaron a la conclusión de que el tiroteo fue orquestado por francotiradores ocultos. En la versión detallada por la Plataforma de Estudio e Investigación de Conflictos Campesinos (PEICC, 2012) se argumenta que los policías, quienes vestían chalecos antibalas, fueron asesinados por disparos en la cabeza y en el cuello. 
proclamadas por portavoces de alto rango entre los productores de soja (como Héctor Cristaldo, jefe de la UGP, así como portavoces de Cargill y de Monsanto), culparon a Lugo por las muertes y pidieron su destitución inmediata (Última Hora, 2012). Dado que la posición de Lugo con respecto a la legislatura nunca fue sólida, no resulta sorprendente que la oposición atacara al surgir la oportunidad y que Lugo no pudiese resistir el ataque.

\section{Retroceso democrático: restablecimiento del statu quo (2012-2018)}

Tras la impugnación y destitución de Fernando Lugo en junio de 2012 hubo una autorización relámpago para el cultivo de un variado número de semillas transgénicas; sólo durante la breve presidencia interina de Federico Franco hubo ocho nuevas aprobaciones. La administración de Cartes (2013-2018) restableció a Paraguay dentro de la ortodoxia neoliberal de la política latinoamericana, junto con México, Chile, Perú, Colombia y la mayoría de los países de América Central (López y Vértiz, 2015). ${ }^{23}$ Desde que asumió la presidencia en agosto de 2013 el gobierno de Horacio Cartes reforzó el papel represivo del gobierno, como la criminalización del movimiento campesino (Areco y Palau, 2016). La criminalización en este contexto se caracteriza no tanto por el uso manifiesto de la fuerza policial o de las milicias armadas para reprimir la protesta social (Palau, 2007), como por la judicialización, esto es, el sometimiento de los campesinos

${ }^{23}$ Un análisis similar de Petras y Veltmeyer (2015:140) sitúa a Paraguay dentro de los «regímenes coloniales-extractivos». 


\section{Arturo Ezquerro-CAÑete}

al código penal utilizando un repertorio creciente de acusaciones (Areco y Palau, 2016). Según recogen estos autores, entre 2004 y 2012 hubo cuatro cargos, mientras que en los dos primeros años de la administración de Cartes (2013-2018) los casos de judicialización aumentaron a 39.

El ambiente político y económico posterior al golpe aseguró un buen «caldo de cultivo» para la continuada agitación campesina en su lucha por la reforma agraria y para la creciente presencia de grupos armados insurgentes. Esta forma de lucha de clases está en aumento en Paraguay. El autoproclamado Ejército del Pueblo Paraguayo (EPP), un movimiento insurgente que opera en el norte del país desde mediados de la década de 2000 (véase Nickson, 2019), ha estado en el centro de varios episodios oscuros en la historia reciente, que incluyen el secuestro y asesinato de Cecilia $\mathrm{Cu}$ bas, hija del expresidente Raúl Cubas (1998-1999). Otro trágico incidente ocurrió el 27 de agosto de 2016, el cual involucró un ataque mortal a una patrulla de la Fuerza de Tarea Conjunta (FTC). El vehículo patrullero fue alcanzado por una bomba colocada en la cuneta cuando viajaba por una carretera secundaria en el área de Arroyito, en el municipio de Horqueta (departamento de Concepción), en la llamada «área de influencia» del EPP. Ocho soldados fueron asesinados en el ataque y los que sobrevivieron a la explosión fueron asesinados a tiros por hombres armados ocultos; se trata del ataque más mortífero perpetrado por este grupo insurgente contra las fuerzas de seguridad hasta la fecha. Este ataque es un claro reflejo de la creciente explosividad del conflicto en la lucha por la tierra. Indudablemente, existe un riesgo de que haya más explosiones de ese tipo en los años venideros. 


\section{Conclusión}

A lo largo del presente trabajo he analizado aspectos clave del contexto histórico, económico, político y social que han contribuido a la lucha en curso por la tierra y por la consolidación de la democracia en Paraguay. Después de casi tres décadas de transición democrática, Paraguay se ha estancado en una etapa ampliamente conocida como «democracia defectuosa», caracterizada por el clientelismo, los enclaves autoritarios y la inequidad (Merkel, 2004; Lambert, 2011). El derrocamiento de Fernando Lugo como presidente de la república revela el desmesurado nivel de influencia ejercido por la élite terrateniente sobre la política paraguaya, así como la débil naturaleza de la democracia del país. La vehemencia de la oposición a un presidente de centro-izquierda, cuyas políticas eran más socialdemócratas que revolucionarias y que en realidad lograban muy poco, sirve de poderoso recordatorio de que «apenas resulta necesario que los gobiernos latinoamericanos adopten medidas socio-revolucionarias antes de que la élite tradicional (...) se sienta amenazada y actúe violentamente en defensa de sus intereses» (Gordon y Webber, 2013:36).

En términos generales, puede afirmarse que la experiencia paraguaya es un poderoso recordatorio de cuán frágiles siguen siendo las perspectivas de una reforma agraria redistributiva, en el periodo post-autoritario y post-neoliberal de la política latinoamericana. Sin abordar el legado del Estado predatorio en Paraguay, y comprender cómo la estructura de poder dejada por este legado se entrelaza con nuevos regímenes de acumulación (capitalismo extractivo) en una economía política más amplia, el actual modelo de exportación agroextractivista continuará reproduciendo las condiciones de una lucha de clases arraigada en las relaciones de 


\section{Arturo Ezquerro-CAÑEte}

explotación de clase e injusticia rural. Bajo esas condiciones, ni siquiera las políticas redistributivas de un régimen neodesarrollista progresista y post-neoliberal pueden funcionar para mantener la paz. Con una clase obrera y un campesinado movilizados, la clase dominante probablemente tendrá que recurrir a la violencia y a la represión: la lucha de clases desde arriba.

\section{Referencias}

ABC Color (2008, 16 de mayo). «Declaran 'guerra a sojeros y queman bandera brasileña».Recuperado de http://www.abc.com.py/edicion-impresa/politica/ declaran-guerra-a-sojeros-y-queman-bandera-brasilena-1067111.html

Abente Brun, D. (2009). «Paraguay: the unravelling of one-party rule». Journal of Democracy, 20(1), 143-156.

Areco, A. y Palau, M. (2016). Judicialización y violencia contra la lucha campesina (2013-2015). BASE Investigaciones Sociales.

Baer, W. y Birch, M.H. (1984). «Expansion of the economic frontier: Paraguayan growth in the 1970s». World Development, 12(8), 783-798.

Banco Mundial (2007). World development report: agriculture for development. Birch, M.H. (2014). «Paraguay and Mercosur: the lesser of two evils?» Latin American Business Review, 15(3-4), 269-290.

Blanc, J. (2015). «Enclaves of inequality: Brasiguaios and the transformation of the Brazil-Paraguay borderlands». The Journal of Peasant Studies, 42(1), 145-158. Borras, S.M., Kay, C., Gómez, S. y Wilkinson, J. (2012). «Land grabbing and global capitalist accumulation: key features in Latin America». Canadian Journal of Development Studies, 33(4), 402-416. 
Bourscheid, J.I. (2016). «Entre la hegemonía y el cesarismo: un análisis gramsciano del gobierno de Fernando Lugo (2008-2012)». Pensamiento Plural, 17, 51-76.

Cannon, B. (2016). The right in Latin America: elite power, hegemony and the struggle for the state. Routledge.

Centro de Documentación y Estudios (2007). Informativo Campesino, 231.

Comisión Económica para América Latina y el Caribe (varios años). Economic Survey of Latin America and the Caribbean.

Coordinadora de Derechos Humanos del Paraguay (Codehupy) (2007). Informe Chokokue 1989-2005.

Coordinadora de Derechos Humanos del Paraguay (Codehupy) (2012). Informe de derechos humanos sobre el caso Marina Kue.

Comisión de Verdad y Justicia (CVJ) (2008). Informe final: tierras mal habidas, tomo IV.

Dirección General de Estadística, Encuestas y Censos (DGEEC) (2004). Principales resultados del censo 2002: vivienda y población.

Dirección General de Estadística, Encuestas y Censos (DGEEC) (2013). Censo nacional de población y viviendas: pueblos indígenas en el Paraguay, resultados preliminares 2012.

Elgert, L. (2016). «More soy on fewer farms» in Paraguay: challenging neoliberal agriculture's claims to sustainability». The Journal of Peasant Studies, 43(2), $537-561$.

Ezquerro-Cañete, A. (2016a). «Poisoned, dispossessed and excluded: a critique of the neoliberal soy regime in Paraguay». Journal of Agrarian Change, 16(4), 702-710.

Ezquerro-Cañete, A. (2016b). «Envenenados, desposeídos y excluidos: una crítica al régimen sojero neoliberal en Paraguay». Estudios Críticos del Desarrollo, 6(11), 151-170. 


\section{Arturo Ezquerro-CAÑete}

Ezquerro-Cañete, A. (2018). «Paraguay: class struggle on the extractive frontier».

En J. Petras y H. Veltmeyer (comps.), The class struggle in Latin America: making history today (pp. 182-206). Routledge.

Ezquerro-Cañete, A. y Fogel, R. (2017). «A coup foretold: Fernando Lugo and the lost promise of agrarian reform in Paraguay». Journal of Agrarian Change, $17(2), 279-295$.

Ezquerro-Cañete, A. y Fogel, R. (2018). «Un golpe anunciado: Fernando Lugo y la promesa perdida de la reforma agraria en Paraguay». En C. Kay y L. Vergara-Camus (comps.), La cuestión agraria y los gobiernos de izquierda en América Latina. Campesinos, agronegocio y neodesarrollismo (pp. 89-118). Consejo Latinoamericano de Ciencias Sociales.

Fogel, R. (2009). «El gobierno de Lugo, el parlamento y los movimientos sociales».

Observatorio Social de América Latina (25), 51-63.

Fogel, R. (2012). «El movimiento de los carperos». Novapolis (5), 11-30.

Fogel, R. (2013). Las tierras de Nacunday, Marina Kue y otras calamidades. Centro de Estudios Rurales Interdisciplinarios; Servi Libro.

Fogel, R. (2015). «Clases sociales y poder político en Paraguay». Novapolis (8), 103-116.

Fogel, R. (2019). «Desarraigo sin proletarización en el agro paraguayo». Íconos (63), 37-54.

Fogel, R. y Riquelme, M. (comps.) (2005). Enclave sojero: merma de soberania y pobreza. Centro de Estudios Rurales Interdisciplinarios.

Galeano, E. (1973). The open veins of Latin America: five centuries of the pillage of a continent. Monthly Review.

Galeano, L.A. (2012). «Paraguay and the expansion of Brazilian and Argentinian agribusinesses frontiers». Canadian Journal of Development Studies, 33(4), 458-470. 
González Bozzolasco, I. (2005). «Peasant in Paraguay fight for land, end of repression». The Militant, 69(5).

González Bozzolasco, I. (2009). «¿Bonapartismo a la Paraguaya?». Novapolis (4), 37-50.

Gordon, T. y Webber, J.R. (2013). «Post-Coup Honduras: Latin America’s corridor of reaction». Historical Materialism, 21(3), 16-56.

Gramsci, A. (1971). Selections from the prison notebooks. International Publishers. Guereña, A. (2013). The soy mirage: the limits of corporate social responsibility: the case of the company Desarrollo Agrícola del Paraguay. Oxfam.

Hetherington, K. (2009). «The strategic incoherence of development: marketing expertise in the world development report». The Journal of Peasant Studies, 36(3), 653-661.

Hetherington, K. (2011). Guerrilla auditors: the politics of transparency in neoliberal Paraguay. Duke University Press.

Hetherington, K. (2013). «Beans before the law: knowledge practices, responsibility, and the Paraguayan soy boom». Cultural Anthropology, 28(1), 65-85.

Hetherington, K. (2014). «Regular soybeans: translating and framing in the ontological politics of a coup». Indiana Journal of Global Legal Studies, 21(1), 55-78. Katz, C. (2007). «Socialist strategies in Latin America». Monthly Review, 59(4), $25-41$.

Kleinpenning, J.M.G. (1984). «Rural development policy in Paraguay since 1960». Tijdschrift voor Eonomische en Sociale Geografie, 75(3), 164-176.

Kleinpenning, J.M.G. y Zoomers, A. (1991). «Elites, the rural masses and land in Paraguay: the subordination of the rural masses to the ruling class». Development and Change, 22(2), 279-295.

Lambert, P. (2005). «Paraguay's enigmatic president». NACLA Report on the Americas, $38(5), 10-12$. 


\section{Arturo Ezquerro-CAÑEte}

Lambert, P. (2011). «Undermining the new dawn: opposition to Lugo in Paraguay». En F. Dominguez, G. Lievesley y S. Ludlam (comps.), Right-wing politics in the new Latin America: reaction and revolt (pp. 177-193). Zed Books.

Lapegna, P. (2017). «The political economy of the agro-export boom under the Kirchners: hegemony and passive revolution in Argentina». Journal of Agrarian Change, 17(2), 313-329.

Latin American Weekly Review (LAWR) (2016, 14 de julio). «Court rules on «Curuguaty massacre»».

Levy, Ch. (2013). «Working towards Tekojojá: the political struggles of the Paraguayan left». Studies in Political Economy, 92(1), 29-56.

López, E. y Vértiz, F. (2015). «Extractivism, transnational capital and subaltern struggles in Latin America». Latin American Perspectives, 42(5), 152-168.

Ministerio de Agricultura y Ganadería (MAG) (2009). Censo agropecuario nacional de 2008.

Marini, R.M. (1972). «Brazilian subimperialism». Monthly Review, 23(9), 14-24.

Merkel, W. (2004). «Embedded and defective democracies». Democratization, $11(5), 33-58$.

Nagel, B.Y. (1999). «Unleashing the fury»: the cultural discourse of rural violence and land rights in Paraguay». Comparative Studies in Society and History, 41(1), 148-181.

Nickson, A. (1981). «Brazilian colonization of the eastern border region of Paraguay». Journal of Latin American Studies, 13(10), 111-131.

Nickson, A. (2008). «Una oportunidad para Paraguay: los desafíos de Fernando Lugo». Nueva Sociedad (216), 4-16.

Nickson, A. (2009). «The general election in Paraguay, april 2008», Electoral Studies, 28(1), 145-149. 
Nickson, A. (2010). «Political economy of policymaking in Paraguay». En A. Berry (comp.), Losing ground in the employment challenge: the case of Paraguay (pp. 265-294). Transaction Publishers.

Nickson, A. (2012, 10 de julio). «Paraguay's presidential coup: the inside story». Open Democracy. Recuperado de https://www.opendemocracy.net/en/ paraguays-presidential-coup-inside-story/

Nickson, A. (2015). Historical Dictionary of Paraguay. Lanham y Boulder/Rowman \& Littlefield.

Nickson, A. (2019). «Revolutionary movements in Latin America after the Cold War: the case of the Ejército del Pueblo Paraguayo». Bulletin of Latin American Research.

Nickson, A. y Lambert, P. (2002). «State reform and the «privatized state» in Paraguay». Public Administration and Development, 22(2), 163-174.

O'Shaughnessy, H. y Ruiz Díaz, E.V. (2009). The priest of Paraguay: Fernando Lugo and the making of a nation. Zed Books.

Oliveira, G. de L.T. (2016). «The geopolitics of Brazilian soybeans». The Journal of Peasant Studies, 43(2), 348-372.

Otero, G. (2012). «The neoliberal food regime in Latin America: State, agribusiness transnational corporations and biotechnology». Canadian Journal of Development Studies, 33(3), 282-294.

Palau, M. (2002). «Luchas sociales obligan a retroceder al gobierno y detienen el proceso de privatización». Observatorio Social de América Latina (8), 20-25. Palau, M. (2007). Criminalización a la lucha campesina. BASE Investigaciones Sociales.

Palau, M. y Kretschmer, R. (2004). «La 'guerra de la soja y el avance del neoliberalismo en el campo paraguayo». Observatorio Social de América Latina (13), 105-115. 


\section{Arturo Ezquerro-CAÑEte}

Palau, T. (2010). «La política y su trasfondo: el poder real en Paraguay». Nueva Sociedad (229), 134-150.

Palau, T., Cabello, D., Maeyens, A., Rulli, J. y Segovia, D. (2007). Los refugiados del modelo agroexportador: impactos del monocultivo de soja en las comunidades campesinas paraguayas. BASE Investigaciones Sociales.

Pastore, C. (1972). La lucha por la tierra en el Paraguay. Antequera.

Plataforma de Estudio e Investigación de Conflictos Campesinos (PEICC) (2012). Informe masacre de Curuguaty.

Petras, J. (1997). «Latin America: the resurgence of the left». New Left Review (233), 17-47.

Petras, J. y Veltmeyer, H. (2009). What's left in Latin America. Ashgate.

Petras, J. y Veltmeyer, H. (2014). «Agroextractivism: the agrarian question of the $21^{\text {st }}$ century». En J. Petras y H. Veltmeyer (comps.). Extractive imperialism in the Americas: Capitalism's new frontier (pp. 62-100). Brill.

Petras, J. y Veltmeyer, H. (2015). Power and resistance: US imperialism in Latin America. Brill.

Petras, J. y Veltmeyer, H. (comps.) (2018). The class struggle in Latin America. Making history today. Routledge.

Piñeiro, D.E. (2004). En busca de la identidad: la acción colectiva en los conflictos agrarios de América Latina. Consejo Latinoamericano de Ciencias Sociales.

Riquelme, Q. (2003). Los sin tierra en Paraguay: conflictos agrarios y movimientos campesinos. Consejo Latinoamericano de Ciencias Sociales.

Riquelme, Q. y Vera, E. (2013). La otra cara de la soja: el impacto del agronegocio en la agricultura familiar y la producción de alimentos. Proyecto Acción Ciudadana contra el Hambre y por el Derecho a la Alimentación.

Rojas, L. (2014). La tierra en disputa: extractivismo, exclusión y resistencia. BASE Investigaciones Sociales. 
Santos, F. y Guarnieri, F. (2016). «From protest to parliamentary coup: an overview of Brazil's recent history». Journal of Latin American Cultural Studies, 25(4), 485-494.

Setrini, G. (2011). «Veinte años de democracia electoral en Paraguay: del clientelismo monopólico al clientelismo plural». En F. Masi y D. Borda (comps.), Estado y economía en Paraguay 1870-2010 (pp. 327-399). Centro de Análisis y Difusión de la Economía Paraguaya.

Última Hora (2008, 14 de octubre). «Decreto Lude da Silva: Brasil amenaza a Paraguay y vecinos». Recuperado de https://www.ultimahora.com/decretolula-da-silva-brasil-amenaza-paraguay-y-vecinos-nl62353.html

Última Hora (2012, 22 de junio). «Los agroempresarios apoyan proceso de destitución del presidente Lugo». Recuperado de https://www.ultimahora. com/los-agroempresarios-apoyan-proceso-destitucion-del-presidentelugo-n538880.html

Veltmeyer, H. y Petras, J. (2014). «A new model or extractivist imperialism?». En H. Veltmeyer y J. Petras (comps.). The new extractivism: a post-neoliberal development model or imperialism of the twenty-first century (pp. 21-46). Zed Book.

Veltmeyer, H. y Petras, J. (2015). «Imperialism and capitalism: rethinking an intimate relationship». International Critical Thought, 5(2), 164-182.

Vergara-Camus, L. y Kay, C. (2018). «Agronegocio, campesinos, Estado y gobiernos de izquierda en América Latina: introducción y reflexiones teóricas». En C. Kay y L. Vergara-Camus (comps.), La cuestión agraria y los gobiernos de izquierda en América Latina: campesinos, agronegocio y neodesarrollismo (pp. 15-49). Consejo Latinoamericano de Ciencias Sociales.

Viveros, D. (2012). «Conamuri: developments and challenges in the struggle against agrochemicals in Paraguay». Environmental Justice, 5(2), 98-99. 


\section{Arturo Ezquerro-CAÑEte}

Vuyk, C. (2014). Subimperialismo brasileño y dependencia del Paraguay: los intereses económicos detrás del golpe de Estado de 2012. Cultura y Participación.

Weisskoff, R. (1992). «The Paraguayan agro-export model of development». World Development, 20(10), 1531-1540.

Wood, E.M.(1999). The origin of capitalism. Monthly Review Press.

Yates, J.S. y Bakker, K. (2014). «Debating the «post-neoliberal turn` in Latin America». Progress in Human Geography, 38(1), 62-90.

Zibechi, R. (2014). The new Brazil: regional imperialism and the new democracy. AK Press. 